ARTICLE

\title{
A Study of Released Radionuclide in the Coastal Area from a Discharge Pipe of Nuclear Fuel Reprocessing Plant in Rokkasho, Aomori, Japan
}

\author{
Takuya KOBAYASHI ${ }^{1, *}$, Teiji IN ${ }^{2}$, Yoichi ISHIKAWA ${ }^{3}$, Hideyuki KAWAMURA ${ }^{1}$, Tomoharu NAKAYAMA ${ }^{2}$, \\ Shigeki SHIMA ${ }^{2}$, Toshiyuki AWAJI ${ }^{3}$ and Orihiko TOGAWA ${ }^{1}$ \\ ${ }^{1}$ Japan Atomic Energy Agency, 2-4 Shirakata Shirane, Tokai-mura, Naka-gun, Ibaraki-ken, 319-1195, Japan \\ ${ }^{2}$ Japan Marine Science Foundation, 4-24 Minato-Machi, Mutsu-si, Aomori-ken, 035-0064, Japan \\ ${ }^{3}$ Kyoto University, Kitashirakawa Oiwake-chou, Sakyo-ku, Kyoto-fu, 606-8502, Japan
}

\begin{abstract}
A numerical simulation model system that consists of an ocean general circulation model and a particle random-walk model with the buoyant plume rise model to describe the radionuclide migration behavior in the off Rokkasho-mura, Aomori-ken, Japan, where a spent nuclear fuel reprocessing plant will start the operation in near future, has been developed. The system has been applied to simulate the nowcast of Rokkasho coastal region in 2007 and a hypothetical radionuclide release has been carried out. The results of model application showed that despite its simplicity, the plume rise model gives relatively detailed calculation and is sufficient for the estimation of plume rise from the discharge pipe. The validation of reanalysis data and application to the several seasons are the topic of our further study.
\end{abstract}

KEYWORDS: spent nuclear fuel reprocessing plant, ocean general circulation model, particle random-walk model, coastal ocean, nesting

\section{Introduction}

A spent nuclear fuel reprocessing plant in Rokkasho-mura, Aomori prefecture will start the operation in near future. The plant releases radioactive waste waters from a discharge pipe to the coastal region, the east of Shimokita Peninsula, during its routine operations. The shape of initial flow is classed as buoyant jets and immediately changes its shape from buoyant jets to plumes.

The authors have developed an oceanic radionuclide migration prediction code system to assess the migration behavior of radionuclide around the coastal region of Aomori prefecture. ${ }^{1)}$ The system performs hind-cast analysis with reanalysis data which are calculated from four-dimensional data assimilation technique. This system assumed that the waste water was not released from a discharge pipe at the adjacent seafloor but from the sea surface. In the period of model validation, the differences of surface concentration of waste water between the calculation results and observation data were found at the neighboring discharge area. A correct estimation of buoyant plume rise is one of the basic requirements for the determination of surface concentrations of waste waters emitted from discharge pipe.

The objective of this work is to extend the previous model to buoyant plume rise model. It has been applied to studying the dispersion of ${ }^{3} \mathrm{H}$. The dispersion of this radionuclide, which is released from the discharge pipe, at the off Shimokita region has not been studied before with the reanalysis data. Also, the effectiveness of the buoyant plume rise model

*Corresponding author, E-mail: kobayashi.takuya38@jaea.go.jp on this calculation period has been examined.

The model is presented in the next section. Thereafter, the results are presented and discussed.

\section{Numerical Models}

\section{Ocean General Circulation Model}

The three-dimensional ocean general circulation model is presented in Toyoda et al.,2) and is not repeated here. They use $\sigma$-z hybrid system in vertical coordinate and Takano-Onishi scheme ${ }^{3)}$ in equation of motion. Mixed layer scheme based on turbulence closure, isopycnal diffusion and eddy parameterization and third-order advection scheme are used in the equation of tracer. Four-dimensional variational adjoint method is used as the data assimilation system to execute the hind-cast analysis. ${ }^{4)}$

As shown in Fig. 1, downscaling calculation by using a nesting method was carried out to derive the results of near Shimokita model. First, downscale calculation starts from the largest area model which includes whole North Pacific and a part of the South Pacific. The resolution of the model is $1 / 6$ degree in longitudinal direction and $1 / 8$ degree in latitudinal one. This model is forced by climatological surface conditions developed by Ocean Model Inter- comparison Project (OMIP). Secondly, the northwestern part of the North Pacific Model assimilates observation data. It has the same resolution as the North Pacific Model. Thirdly, the Near Japan Model runs by using output of the northwestern part of the North Pacific Model. The resolution of the model is $1 / 18$ degree in longitudinal direction and $1 / 24$ degree in

(C) 2011 Atomic Energy Society of Japan, All Rights Reserved. 

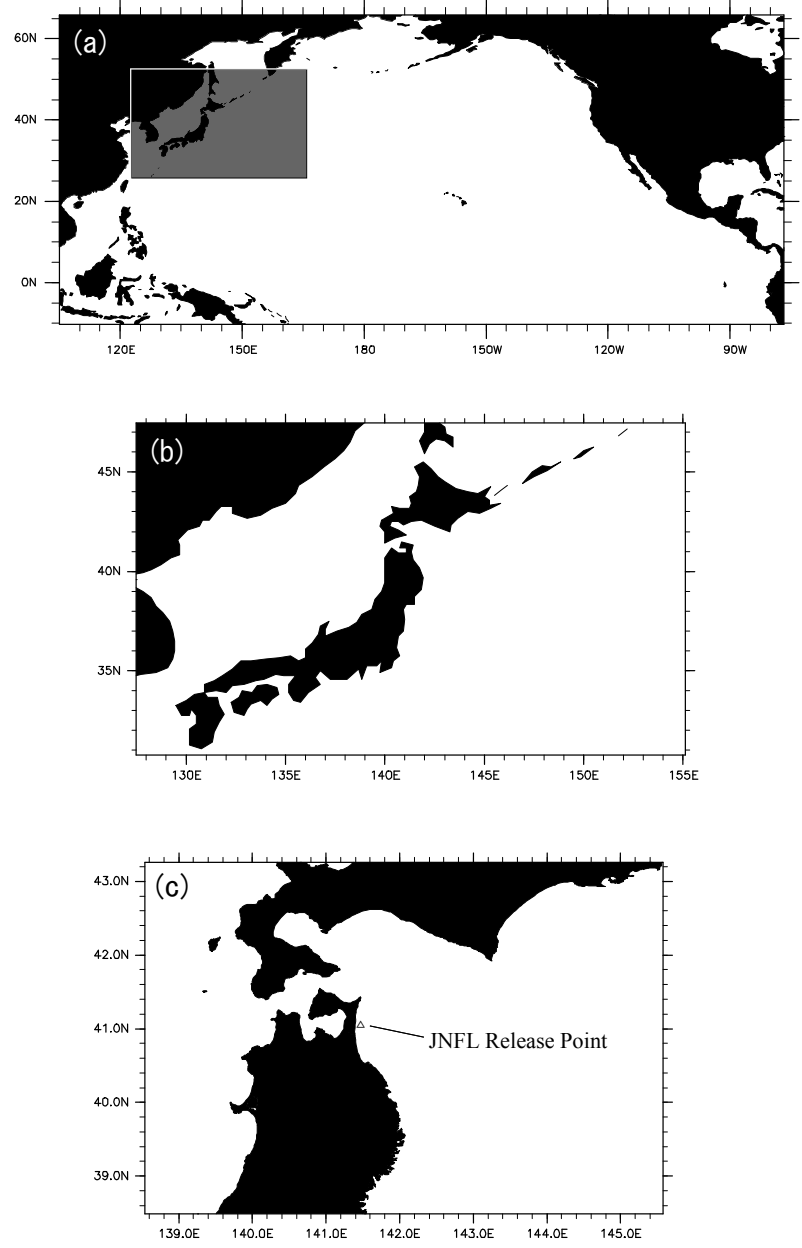

Fig. 1 The domains of the system: (a) North Pacific Model, (b) Near Japan Model and (c) Near Shimokita Model. The grey area in (a) represents the domain of the northwestern North Pacific Model, to which data assimilation is applied.

latitudinal one. The dairy mean reanalysis dataset by National Centers for Environmental Prediction-Department of Energy (NCEP-DOE Reanalysis 2) is used as the surface boundary condition of these models. Finally, the Near Shimokita Model runs by using output of the Near Japan Model. The surface conditions used in this model are NCEP-DOE Reanalysis 2 for air temperature, humidity, cloud cover, short wave radiation and precipitation, and Mesoscale Reanalysis dataset by Japan Meteorological Agency for wind. The resolution of this model is about $1.5 \mathrm{~km}$ in both directions. The number of vertical layer is 78 for all models.

\section{Radionuclide Dispersion Model}

A particle random-walk model, SEA-GEARN is used as a radionuclides dispersion model in the ocean. ${ }^{5)}$ The SEA-GEARN uses three-dimensional velocity data calculated by ocean general circulation model as the input variables. If non-conservative radionuclides are concerned, interactions with the large particulate matter (LPM) must be considered. To take these situations into account, a new model that solves three phases interaction, developed by Periáñez, ${ }^{6}$ has been adopted in the SEA-GEARN. The three phases of radionuclides consists of dissolved in seawater, adsorbed with LPM and adsorbed with active bottom sediment, respectively. This model has the following assumptions; (1) LPM is the aggregate which has a single radius and density, (2) the movement of each particle is decided by velocity, diffusivity and settling velocity of particle itself.

The plume rise model is added to the particle transport equation of $z$-direction. The particle position $(x, y, z)_{t+\Delta t}$ is computed at each time step $\Delta t$ as follows:

$$
\begin{array}{r}
x(t+\Delta t)=x(t)+u(t) \Delta t+\sqrt{24 K_{H} \Delta t}(0.5-R(0)) \\
y(t+\Delta t)=y(t)+v(t) \Delta t+\sqrt{24 K_{H} \Delta t}(0.5-R(0)) \\
z(t+\Delta t)=z(t)+w(t) \Delta t \\
\quad+\sqrt{24 K_{z} \Delta t}(0.5-R(0))+w_{B} \Delta t
\end{array}
$$

where $u(t)$ and $v(t)$ represents the horizontal velocity and $w(t)$ the velocity, $K_{H}$ and $K_{z}$ the horizontal and vertical diffusion coefficient, respectively, $R(0)$ the uniform random number between 0 and 1 , and $w_{B}$ the plume rise velocity given by ${ }^{7)}$

$$
w_{B}=\frac{H_{p}(u, s, t+\Delta t)-H_{p}(u, s, t)}{\Delta t}
$$

where $H_{p}$ is the rise of plume centerline with time. Plume rise formula is given by

$$
H_{p}(u, s, t)=2.6\left(\frac{\bar{F} t^{2}}{\bar{u}}\right)^{1 / 3}\left(t^{2} s+4.3\right)^{-1 / 3}
$$

where $\bar{u}$ is the mean current velocity. $\bar{F}$ and $s$ are the mean flux of buoyancy and the density stratification parameter given by

$$
\begin{aligned}
& \bar{F}=g w_{0} \pi r^{2} \frac{\rho_{a}-\rho_{0}}{\rho_{a}}, \\
& s=-\frac{g}{\rho_{0}} \frac{d \rho_{a}}{d z}
\end{aligned}
$$

where $g$ is the gravitational acceleration, $w_{0}$ the discharge velocity, $r$ the radius of the orifice and $\rho_{a}$ and $\rho_{0}$ the ambient and discharge densities, respectively.

The plume rise velocity equation (4) is not used when the ambient environment is motionless, and a buoyancy-induced velocity is used:

$$
w_{B}=\frac{1}{2} g \frac{\rho_{a}-\rho_{0}}{\rho_{a}} \Delta t
$$

The plume rise height is derived by the relation between density stratification of ambient water and $\bar{F}$. The plume rise height is set as sea surface when the vertical density profile is uniform. 


\section{Numerical Experiments}

\section{Calculation Condition of the Ocean General Circula- tion Model}

One month calculation was performed with the Near Shimokita Model. Calculation period is from November 6 to December 6, 2007. The current data were output every three hours and provided to SEA-GEARN.

\section{Release Condition of the Radionuclide Dispersion Model}

The migration of ${ }^{3} \mathrm{H}$ released from the discharge pipe of spent nuclear fuel reprocessing plant of Japan Nuclear Fuel Limited (JNFL) in Rokkasho was simulated. The model grid is the same as the Near Shimokita Model of ocean general circulation model and time step is one second.

For the model simulations, the realistic discharge quantities from the plant from November 6 to December 4, 2007 have been used. The JNFL had opened release information of gaseous/liquid waste materials to atmosphere and ocean in their web site (http://www.jnfl.co.jp/index.html). Since no information about the discharge duration was obtained, the continuous discharge from 10:00 to 16:00 was assumed to all of discharge event. Table 1 shows the discharge quantities of liquid ${ }^{3} \mathrm{H}$ to ocean environment from the JNFL spent nuclear fuel reprocessing plant in Rokkasho. The diameter of discharge pipe is $7.5 \mathrm{~cm}$, the discharge pipe height is $3 \mathrm{~m}$ above the sea floor and the waste water density of $1000 \mathrm{~kg} / \mathrm{m}^{3}$ is assumed. The horizontal and vertical diffusion coefficients are taken as 1.0 and $0.005 \mathrm{~m}^{2} / \mathrm{s}$, respectively, which is derived from previous model validations. The released particle numbers in this calculation are one million.

\section{Results and Discussion}

(1) Near Field Distribution

Figure 2 shows the vertical distribution of particles which were released 10 minutes, 1 hour and 10 hours after the first discharge of waste water from the orifice on 10:00 at November 6, 2007. The particles which were released from $3 \mathrm{~m}$ above the sea bottom transferred upward with straight shape by the little horizontal current (Fig. 2(a)). They arrived at the maximum plume rise height of $15 \mathrm{~m}$ and stopped the plume

Table 1 Discharge quantities of liquid ${ }^{3} \mathrm{H}$ from the JNFL spent nuclear fuel reprocessing plant

\begin{tabular}{lcc}
\hline Date & $\begin{array}{c}\text { Discharge of } \\
\text { waste water }\left(\mathrm{m}^{3}\right)\end{array}$ & $\begin{array}{c}\text { Radioactivity of }{ }^{3} \mathrm{H} \\
(\mathrm{Bq})\end{array}$ \\
\hline Nov. 6, 2007 & 580.3 & $7.8 \times 10^{12}$ \\
Nov. 9, 2007 & 582.4 & $9.6 \times 10^{12}$ \\
Nov. 14, 2007 & 572.2 & $4.2 \times 10^{13}$ \\
Nov. 17, 2007 & 586.3 & $9.8 \times 10^{13}$ \\
Nov. 20, 2007 & 543.1 & $5.9 \times 10^{13}$ \\
Nov. 29, 2007 & 572.8 & $4.9 \times 10^{13}$ \\
Dec. 4, 2007 & 589.0 & $2.3 \times 10^{13}$ \\
\hline
\end{tabular}

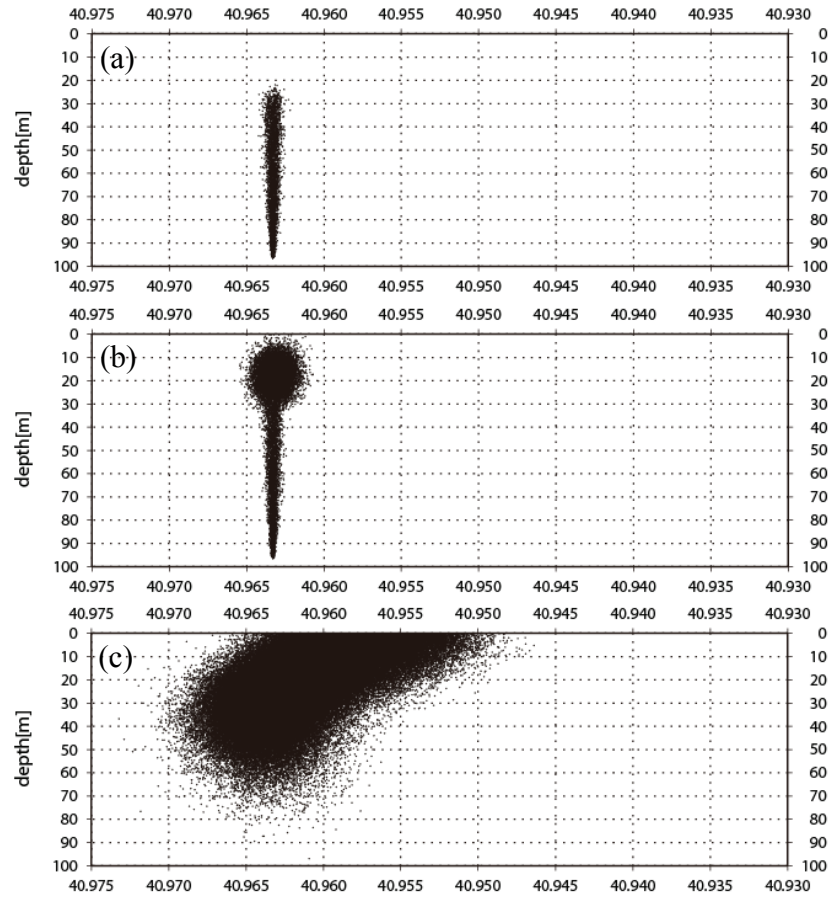

Fig. 2 Vertical distribution of particles which were released (a) 10 minutes, (b) 1 hour and (c) 10 hours after the first discharge of waste water from the orifice on 10:00 at November 6, 2007. Model, to which data assimilation is applied.

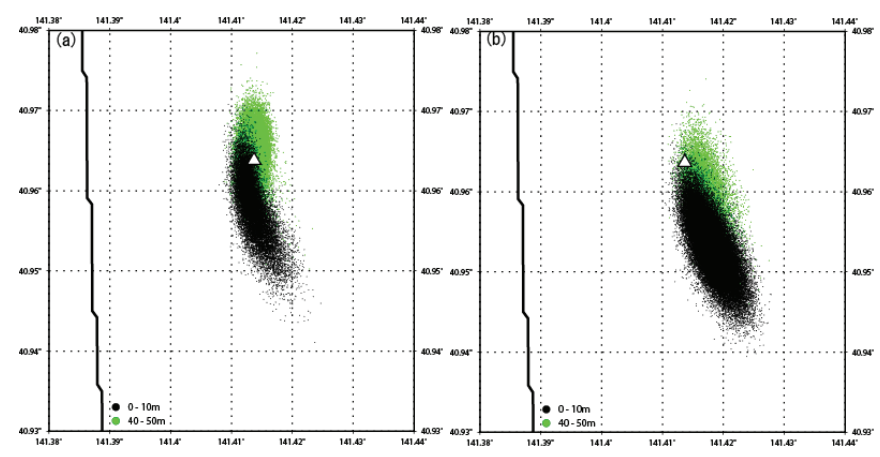

Fig. 3 Two layers (0-10 $\mathrm{m}$ and 40-50 $\mathrm{m}$ ) horizontal distribution of particles which were released 14 hours after the first discharge of waste water from the orifice on 10:00 at November 6, 2007 (a) with plume rise model and (b) without plume rise model (particles were released from sea surface). The release point is shown as triangle.Model, to which data assimilation is applied.

rise (Fig. 2(b)). Figure 2(c) illustrates the differences of the horizontal current at the surface and subsurface layer in the close area of discharge pipe. The wind-driven current moved the surface particles to the south. It can be found from this figure that there is a definite difference of migration pattern between the releases from surface and from sea bottom. The actual depth of release point is $43 \mathrm{~m}$, while bathymetry data indicates $100 \mathrm{~m}$. The adoption of exact bathymetry data remains as one of the key issue to be clarified.

Figure 3 shows two layers $(0-10 \mathrm{~m}$ and $40-50 \mathrm{~m})$ horizontal distribution of particles which were released 14 hours after the first discharge of waste water from the orifice on 

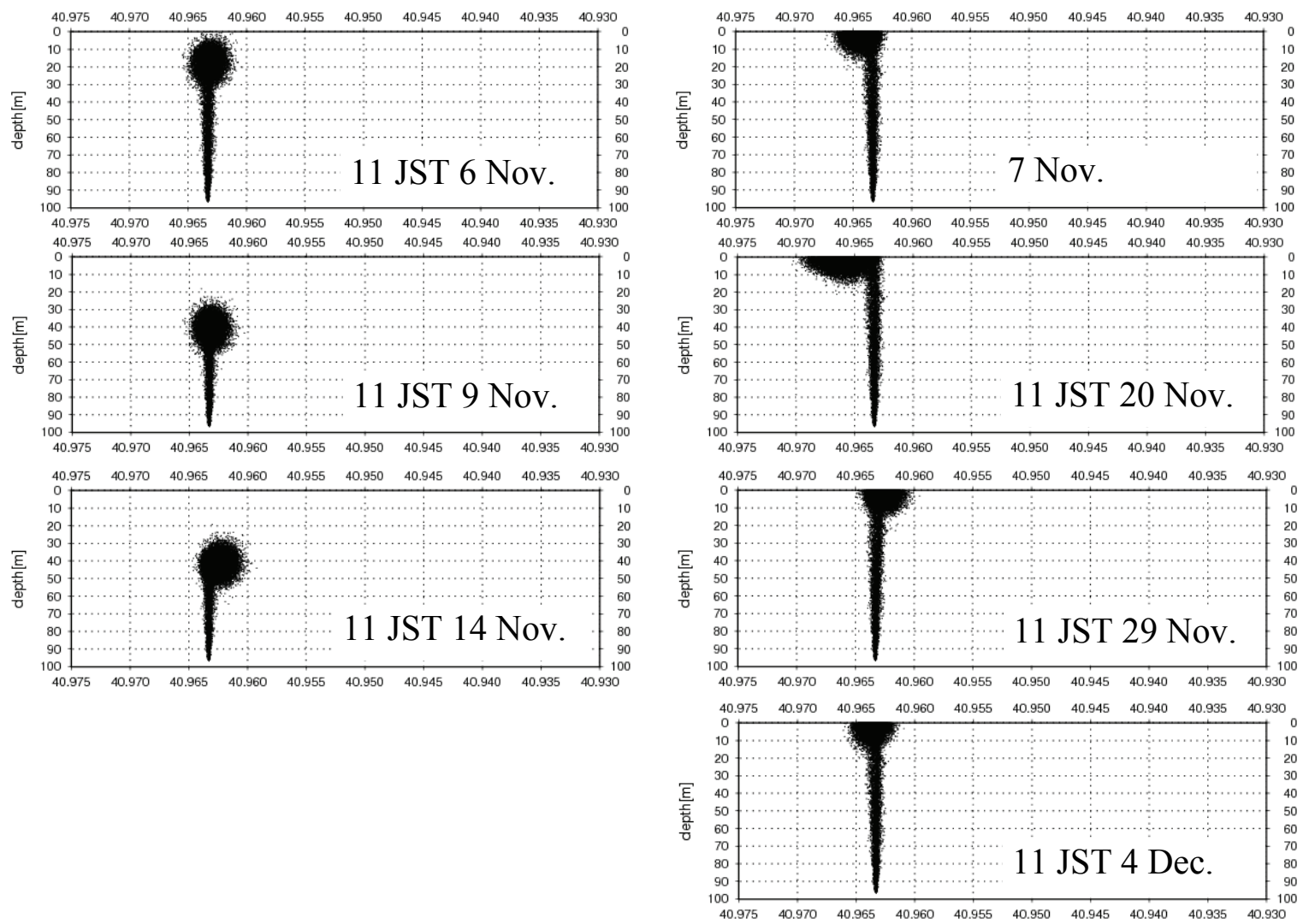

Fig. 4 The vertical distributions of particles which were released 1 hour after the each discharge

10:00 at November 6, 2007 with plume rise model and without plume rise model (surface release calculation), respectively. These figures show that there are clearly differences between the calculation results of the releases from surface and from sea bottom. The calculation results of this period suggested that the plume rise model has an important role in case of the estimation of near field migration processes.

Figure 4 shows the vertical distributions of particles which were released 1 hour after the each discharge. To simplify the visualization process, each discharge events were not calculated continuously but individually on these particular figures. The first part of discharge showed that the released waste water stopped the rising at subsurface (Fig. 4(a)) and middle (Fig. 4(b) and (c)) of the sea. On the other hand, the released waste water arrived at the sea surface on the latter part of discharge (Fig. 4(d)-(g)). These figures show that density stratification was formed at the early period of this model simulation and suddenly vanished for some reason. The weather map on November 15, 2007 which was published by Japan Meteorological Agency ${ }^{8)}$ is presented in Fig. 5, where the weather front passing around the off Shimokita region is shown. It can be seen from this weather map that the strong sea surface wind blew away the off Shimokita region, the wind mixed the stratified water column and uniform vertical density profile was generated.

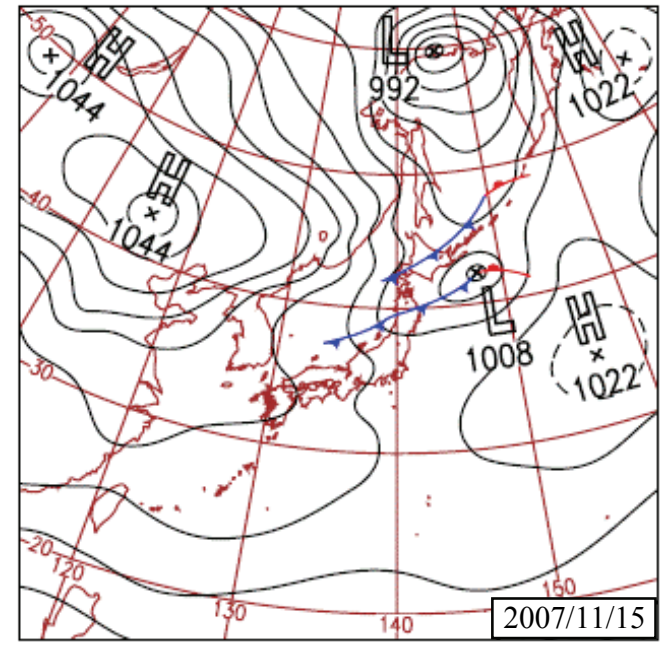

Fig. 5 The weather map on November 15, 2007 which was published by Japan Meteorological Agency.Model, to which data assimilation is applied

From this result, we found that the passing the weather front affects on the form of initial plume rise and this model system can response such a short term event.

(2) Far Field Distribution

Figure 6 shows the surface $(0 \mathrm{~m})$ horizontal distribution of ${ }^{3} \mathrm{H}$ on $10,15,20,25$ and 30 November, 2007, respectively. 


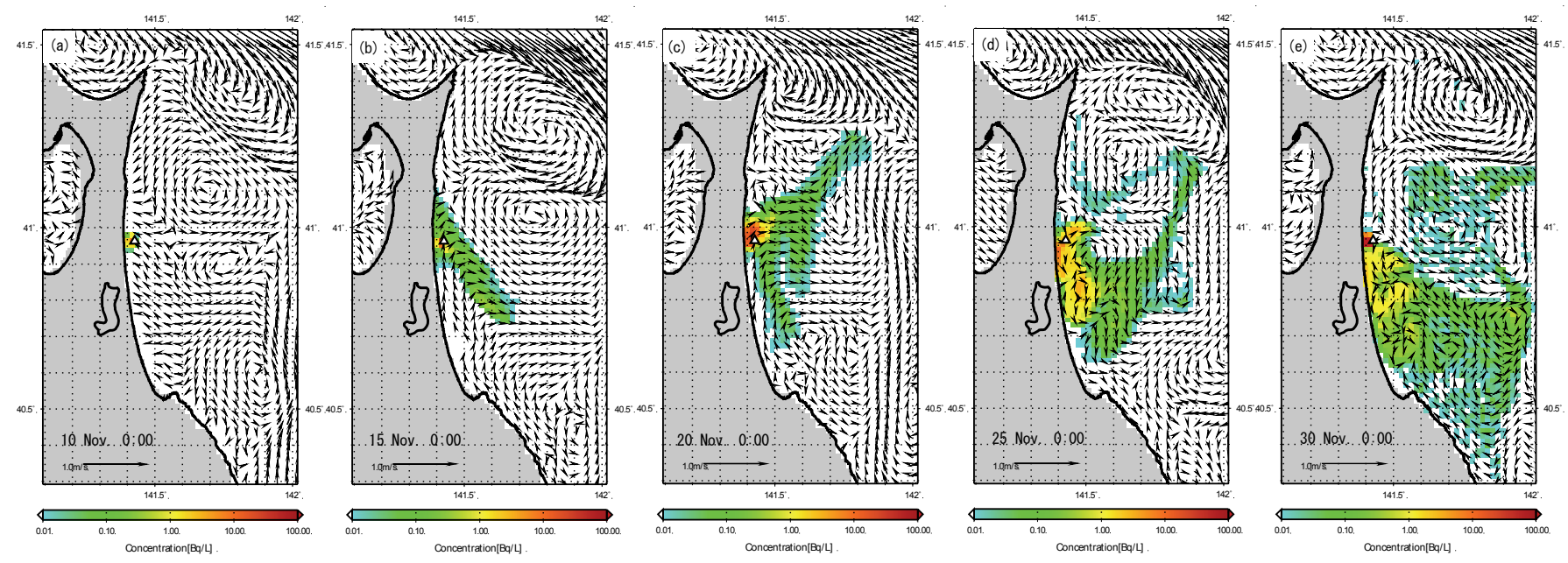

Fig. 6 Surface (0 m) horizontal distribution of ${ }^{3} \mathrm{H}$ on (a) 10, (b) 15, (c) 20, (d) 25, (e) 30 November, 2007

The small current velocity and west-ward current during the period from 6 to 13 November hold the transfer of ${ }^{3} \mathrm{H}$ within the distance of $10 \mathrm{~km}$ from the discharge pipe (Fig. 6(a)). Tritium transferred to the south by the southeast current during the period from 14 to 17 November (Fig. 6(b)). Then, ${ }^{3} \mathrm{H}$ stretched widely to north and south at 20 November (Fig. 6(c)), thereafter ${ }^{3} \mathrm{H}$ dispersed widely and transferred to the south (Fig. 6(d) and (e)).

The above mentioned results were compared with the results of surface release calculation. As a result, those two results have little differences about the migration pattern of surface waste water. As an example, the surface horizontal distribution of ${ }^{3} \mathrm{H}$ on 15 November, 2007 without plume rise model (surface release calculation) is shown in Fig. 7. Comparing Fig. 6(b) with Fig. 7, it is found that the distribution pattern is quite same except around the release point of high concentration area in Fig. 7. This study is examined numerically under the short period on November, 2007. The results obtained in this study appear to be rather case-specific and possible application ranges of this plume rise model to generic cases require further study.

In conclusion, the plume rise model with reanalysis data was found to be very useful tool for detailed assessment of released radionuclides at the coastal region of nuclear fuel reprocessing plant.

\section{Conclusion}

The buoyant plume rise model has been added to the radionuclides dispersion model in the ocean. The plume rise velocity is calculated by the relation of mean flux of buoyancy and density stratification parameter which are derived from gravitational acceleration, discharge velocity, radius of the orifice, ambient density and discharge density.

The results of model application at the off Shimokita region show that despite its simplicity, the plume rise model gives relatively detailed calculation and is sufficient for the estimation of plume rise from the discharge pipe.

The validation of reanalysis data and application to the several seasons are the topic of our further study.

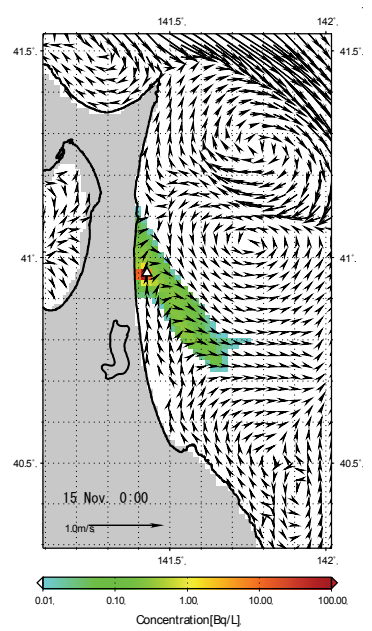

Fig. 7 Surface $(0 \mathrm{~m})$ horizontal distribution of ${ }^{3} \mathrm{H}$ on 15 November, 2007 without plume rise model (surface release calculation)

\section{Acknowledgment}

A part of this work was supported by a contract with the Government of Aomori Prefecture.

\section{References}

1) T. Kobayashi, T. In, Y. Ishikawa, Y. Matsuura, S. Shima, T. Nakayama, T. Awaji, H. Kawamura, O. Togawa. "Development of a system for the prediction of radionuclides migration in the off Shimokita region and its case study," Trans. At. Energy Soc. Japan, 7[2], 112-126 (2008), [in Japanese].

2) T. Toyoda, T. Awaji, Y. Ishikawa, T. Nakamura. "Preconditioning of winter mixed layer in the formation of North Pacific eastern subtropical mode water," Geophys. Res. Lett., 31, doi:10.1029/2004GL020677 (2004).

3) H. Ishizaki, T. Motoi. "Reevaluation of the Takano-Oonishi scheme for momentum advection on bottom relief in ocean models," J. Atmos. Ocean. Tech., 16, 1994-2010 (1999).

4) Y. Ishikawa, T. Awaji, T. Toyoda, T. In, K. Nishina, T. Nakayama, S. Shima. "High-resolution synthetic monitoring by a 
4-dimensional variational data assimilation system in the northwestern North Pacific," J. Marine Sys., 78[2], 237-248 (2009).

5) T. Kobayashi, S. Otosaka, O. Togawa, K. Hayashi. "Development of a Non-conservative Radionuclides Dispersion Model in the Ocean and its Application to Surface Cesium-137 Dispersion in the Irish Sea," J. Nucl. Sci. Technol., 44[2], 238-247 (2007).

6) R. Periáñez. "The dispersion of ${ }^{137} \mathrm{Cs}$ and ${ }^{239,240} \mathrm{Pu}$ in the Rhone
River plume: a numerical model," J. Environ. Radioact., 77[3], 301-324 (2004).

7) D. Anfossi, E. Ferrero, G. Brusasca, A. Marzorati, G. Tinarelli. "A simple way of computing buoyant plume rise in Lagrangian stochastic dispersion models," Atmos. Environ., 27A[9], 1443-1451 (1993).

8) Japan Meteorological Agency, "Daily weather map," http://www.data.jma.go.jp/fcd/yoho/hibiten/index.html (accessed 2010-10-05). 